\title{
Ruptured Dissecting Anterior Inferior Cerebellar Artery Aneurysm
}

\author{
-Case Report- \\ Takeshi MatsuYama, Kazuo OKUCHI, Kazuobu NORIMOTO, \\ and Tohru UEYAMA
}

Department of Emergency and Critical Care Medicine, Nara Medical University, Kashihara, Nara

\begin{abstract}
A 39-year-old woman presented with a rare dissecting aneurysm of the proximal anterior inferior cerebellar artery (AICA). She presented with sudden onset of headache and vomiting, and subsequently became comatose with acute respiratory distress syndrome. Computed tomography showed subarachnoid hemorrhage and ventricular dilation. Left vertebral angiography identified a fusiform aneurysm at the proximal portion of the left AICA. The patient underwent endovascular treatment using Guglielmi detachable coils. The aneurysm was completely embolized. Computed tomography detected no infarcted areas in the regions supplied by the AICA. She was discharged without neurological deficits.
\end{abstract}

Key words: dissecting aneurysm, anterior inferior cerebellar artery

\section{Introduction}

Aneurysm of the anterior inferior cerebellar artery (AICA) is rare, and is usually saccular and located at the meatal loop and around the internal auditory artery. ${ }^{1,4,5,8,10-14)}$ Other locations include the lateral or medial branches of the AICA. ${ }^{8)}$ Dissecting aneurysm of the proximal portion of the AICA is extremely rare. We present a case of a ruptured dissecting aneurysm arising from the proximal portion of the AICA.

\section{Case Report}

A 39-year-old woman was admitted to a local hospital with complaints of sudden onset of severe headache and vomiting on July 14,2000 . She had no past history of head and neck trauma, systemic bacterial infection, hypertension, or malignancy. On admission, she was drowsy but oriented with no other neurological deficits. Slight nuchal rigidity was apparent. Her pupils were isocoric and reacted normally to light. Computed tomography (CT) disclosed a Fisher grade 2 subarachnoid hemorrhage (SAH) distributed mainly in the basal cistern and posterior

Received November 14, 2001; Accepted March 13, 2002 fossa (Fig. 1). Three hours after admission, her consciousness gradually deteriorated to coma. Her respiration was rapid and shallow, suggesting acute

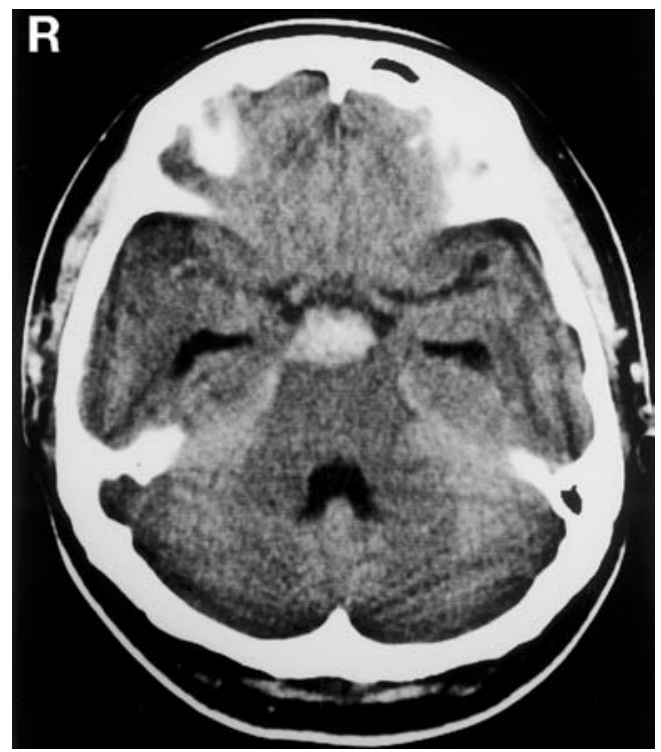

Fig. 1 Computed tomography scan on admission showing severe subarachnoid hemorrhage in the prepontine cistern and posterior fossa. 


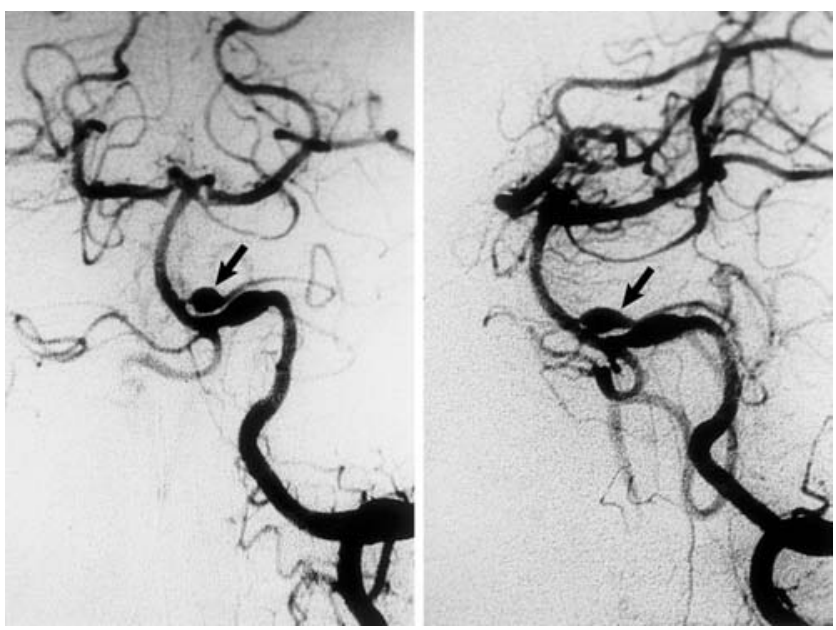

Fig. 2 Preoperative left vertebral angiograms, anteroposterior (left) and lateral views (right), showing a dissecting aneurysm (arrow) at the proximal portion of the left anterior inferior cerebellar artery.

respiratory distress syndrome. She was transferred to our department for treatment of SAH and pulmonary distress.

CT disclosed marked ventricular dilation, suggesting acute hydrocephalus. Emergent ventricular drainage was performed. Left vertebral angiography revealed fusiform aneurysms of the proximal portion of the left AICA and the left intracranial vertebral artery. These findings indicated that the aneurysms were dissecting aneurysms (Fig. 2). The configuration of the basilar artery was normal. Continuous dissection from the vertebral artery to the AICA was excluded. Chest radiography disclosed diffuse pulmonary edema in both lungs. Her respiration was controlled with positive endoexpiratory pressure under sedation. Seven days after admission, her pulmonary function improved markedly.

Nineteen days after admission, left vertebral angiography revealed that the size of the AICA aneurysm had increased, and the vertebral artery aneurysm had slightly shrunk, suggesting that the bleeding originated from the AICA aneurysm and the vertebral artery aneurysm was asymptomatic. Endovascular treatment was selected after multidisciplinary discussions between the neurosurgeons and neuroradiologists, and informed consent was obtained. The AICA aneurysm was trapped using Guglielmi detachable coils (GDCs) (Target Therapeutics, Fremont, Calif., U.S.A.) to prevent life-threatening rebleeding. The aneurysm was trapped with $3 \times$ $100 \mathrm{~mm}, 2 \times 80 \mathrm{~mm}, 2 \times 40 \mathrm{~mm}, 2 \times 60 \mathrm{~mm}$, and $2 \times 40 \mathrm{~mm}$ soft GDCs (Fig. 3). Controlled an-

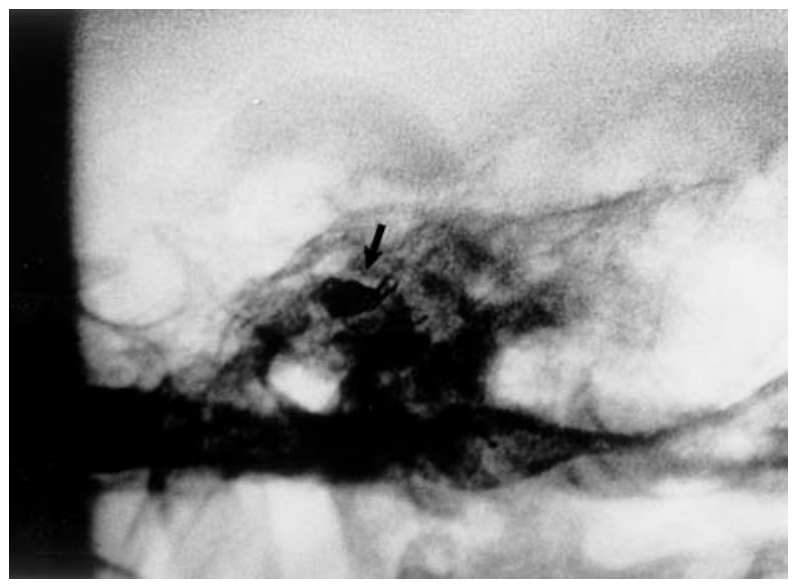

Fig. 3 Left vertebral angiogram showing the aneurysm was trapped using Guglielmi detachable coils (arrow).
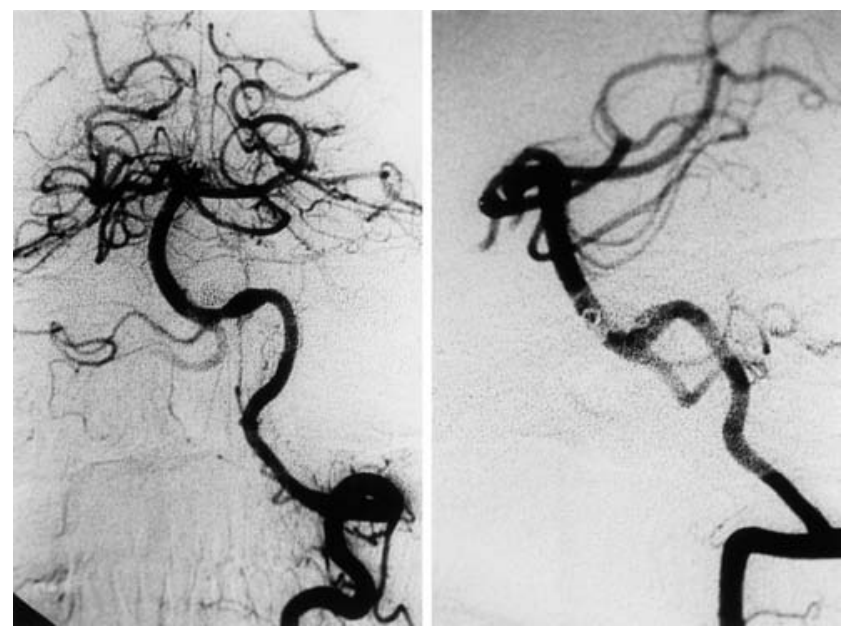

Fig. 4 Left vertebral angiograms after coil embolization, anteroposterior (left) and lateral views (right), showing the aneurysm completely embolized.

giography showed complete trapping of the aneurysm (Fig. 4). The distal AICA was not filled. CT after the coil embolization procedure detected no infarcted areas in the left side of the pons and the left cerebellum. She had no postoperative neurological deficits.

\section{Discussion}

Recently, skull-base surgery techniques have markedly progressed and now allow the treatment of lower basilar artery aneurysms. ${ }^{2,6)}$ However, a direct surgical approach for the AICA aneurysm is 
difficult because of the deep location and adhesion to cranial nerves such as the seventh and the eighth cranial nerves. In our case, the aneurysm was more difficult to approach because of the location on the proximal AICA.

Two thirds of cases of distal AICA aneurysms were treated with neck clipping and the others were trapped. ${ }^{14)}$ Although clipping could be performed successfully, postoperative complications were common, including facial nerve paresis and hearing loss, which may have resulted from nerve damage due to direct manipulation and stenosis or occlusion of the internal auditory artery. ${ }^{8)}$ Several fine perforating vessels arise from the proximal portion of the AICA and penetrate into the pons. Proximal occlusion of the AICA may cause brain stem infarction and cerebellar infarction. However, in our case, the aneurysm was fusiform and could not be treated without trapping.

Endovascular therapy was chosen on the basis of minimal invasiveness. Recently, endovascular treatment using GDCs has been useful for obliterating aneurysms. In particular, endovascular treatment of vertebrobasilar artery saccular aneurysms provides more satisfactory results than direct surgery. ${ }^{3,7,9)}$ However, fusiform or dissecting aneurysm is still difficult to manage without sacrificing the parent artery. We believe that endovascular treatment is the best choice since surgical stress could be avoided in a patient in poor condition. In our case, no ischemic complications occurred due to the sacrifice of the distal AICA because of sufficient collateral circulation from the ipsilateral superior cerebellar artery or posterior inferior cerebellar artery. This strategy cannot be used for all patients. If the collateral circulation is poor or the AICA is well developed, occipital artery-AICA bypass should be performed to prevent ischemic complications before the sacrifice of the AICA.

\section{References}

1) Fukuya T, Kishikawa T, Ikeda J, Kudo S, Kuwano H, Matsumoto S, Fujii K: Aneurysms of the peripheral portion of the anterior inferior cerebellar artery; report of two cases. Neuroradiology 29: 493-496, 1987

2) Giannotta SL, Marceri DR: Retrolabyrinthine transsigmoid approach to basilar trunk and vertebrobasilar artery junction aneurysms: Technical note. J Neurosurg 69: 461-466, 1988

3) Gruber A, Killer M, Bavinski G, Richling B: Clinical and angiographic results of endovascular coiling treatment of giant and very large intracranial aneurysms: A 7-year, single-center experience. Neurosurgery 45: 793-804, 1999

4) Iwanaga S, Shirer DA, Okawara SH, Numaguchi Y: Value of CT angiography in the evaluation of a peripheral anterior inferior cerebellar artery aneurysm: case report. Clin Imaging 23: 77-80, 1999

5) Kamiya K, Nagai H, Koide K, Yamashita N, Shimazu $\mathrm{N}$ : Peripheral anterior inferior cerebellar artery aneurysms. Surg Neurol 42: 46-51, 1994

6) Kawase T, Bertalanffy H, Otani M, Shiobara R, Toya S: Surgical approaches for vertebro-basilar trunk aneurysms located in the midline. Acta Neurochir (Wien) 138: 402-410, 1996

7) Lempert TE, Malek AM, Halbach VV, Phatouros CC, Meyers PM, Dowd CF, Higashida RT: Endovascular treatment of ruptured posterior circulation cerebral aneurysms: clinical and angiographic outcomes. Stroke 31: 100-110, 2000

8) Mizushima H, Kobayashi N, Sawabe $Y$, Hanakawa K, Dohi K, Sasaki K, Matsumoto K: Aneurysm of the distal anterior inferior cerebellar artery at the medial branch: A case report and review of the literature. Surg Neurol 52: 137-142, 1999

9) Pierot L, Boulin A, Castaings L, Rey A, Moret J: Selective occlusion of basilar artery aneurysms using controlled detachable coils: report of 35 cases. Neurosurgery 38: 948-954, 1996

10) Pritz MB: Aneurysms of the anterior inferior cerebellar artery. Acta Neurochir (Wien) 120: 12-19, 1993

11) Saito M, Ezura M, Takahashi A, Yoshimoto T: [An arterial dissection of the distal anterior inferior cerebellar artery treated by endovascular therapy]. No Shinkei Geka 28: 269-274, 2000 (Jpn, with Eng abstract)

12) Saito $R$, Tominaga $T$, Ezura $M$, Shimizu $H$, Yoshimoto T: [Distal anterior inferior cerebellar artery aneurysms: report of three cases and literature review]. No Shinkei Geka 29: 709-714, 2001 (Jpn, with Eng abstract)

13) Schwarz HG: Arterial aneurysm of the posterior fossa. J Neurosurg 5: 312-326, 1948

14) Suzuki K, Meguro K, Wada M, Fujita K, Nose T: Embolization of a ruptured aneurysm of the distal anterior inferior cerebellar artery: case report and review of the literature. Surg Neurol 51: 509-512, 1999

Address reprint requests to: T. Matsuyama, M.D., Department of Emergency and Critical Care Medicine, Nara Medical University, 840 Shijo-cho, Kashihara, Nara 634-8522, Japan.

e-mail: tmatsuya@nmu-gw.naramed-u.ac.jp. 